Research Article

\title{
Post-Mortem Comparison of the Incidence and the Distribution of Cerebrovascular Lesions Using Additional 7.0-Tesla Magnetic Resonance Imaging in Cognitive Normal Young, Middle-Aged, and Elderly Persons
}

\author{
Jacques De Reuck ${ }^{*}$, Florent Auger, Nicolas Durieux, Claude-Alain Maurage, Vincent Deramecourt, \\ Charlotte Cordonnier, Florence Pasquier, Didier Leys, Regis Bordet \\ INSERM Unitè 1171 "Degenerative \& vascular cognitive disorders", Université de Lille 2, Lille, \\ France; E-Mails: dereuck.j@gmail.com; florent.auger@univ-lille2.fr; nicolas.durieux@univ-lille2.fr; \\ CA-MAURAGE@chru-lille.fr; V-DERAMECOURT@chru-lille.fr; C-CORDONNIER@chru-lille.fr; \\ Florence.PASQUIER@chru-lille.fr; didier.leys@chru-lille.fr; R-BORDET@chru-lille.fr
}

* Correspondence: Jacques De Reuck; E-Mail: dereuck.j@gmail.com

Academic Editor: Lisa A. Hollis-Sawyer

\section{OBM Geriatrics}

2020, volume 4, issue 2

doi:10.21926/obm.geriatr.2002122
Received: April 06, 2020

Accepted: May 21, 2020

Published: June 04, 2020

\begin{abstract}
Regional brain atrophy and an escalation in vascular risk are associated to increasing age in normal cognitive healthy persons. The present post-mortem study compares the incidence of cerebrovascular lesions between young-aged, middle-aged, and elderly cognitive normal persons with additional 7.0-tesla MRI). The patients consisted of 10 young adults, 20 middleaged adults, and 14 elderly ones. In addition to the macroscopic visible cerebrovascular lesions, a whole coronal section of a cerebral hemisphere was taken for the semiquantitative evaluation of white matter changes (WMCs), cortical micro-infarcts (CoMIs), and cortical micro-bleeds (CoMBs). Three separate coronal sections of a cerebral hemisphere were submitted to $\mathrm{T} 2$ and $\mathrm{T} 2 * \mathrm{MRI}$ sequences for semi-quantitative evaluation of the small cerebrovascular lesions. Arterial hypertension, hypercholesterolemia, and the use of anti-thrombotic agents were found to be more frequent in the elderly group, and to a lesser degree in the middle-aged group. The neuropathological examination showed more severe WMCs and an increased number of CoMBs in the elderly group. On NMR the
\end{abstract}

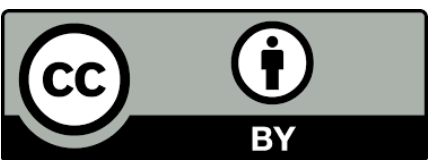

(C) 2020 by the author. This is an open access article distributed under the conditions of the Creative Commons by Attribution License, which permits unrestricted use, distribution, and reproduction in any medium or format, provided the original work is correctly cited. 
increased severity of WMCs was only found in the frontal and occipital sections of the elderly brains. CoMls were augmented in the central and occipital sections of the middleaged and the elderly persons. CoMBs were increased in all coronal sections of elderly as well as middle-aged groups. CoMls reflect most significantly the cerebrovascular involvement of the aging brain. The increase of WMCs is probably mostly related the aging related neurodegenerative progression. The increase of CoMBs is probably due to mixed cerebrovascular and neurodegenerative pathology.

\section{Keywords}

Neuropathology; post-mortem magnetic resonance imaging; normal brain aging; white matter changes; cortical micro-infarcts; cortical micro-bleeds

\section{Introduction}

Recent advances in medicine, global health, and biotechnology have led to prolonged life expectancy and, thus, a rapid aging population [1]. Regional brain atrophy and an escalation in vascular risk are associated to increasing age in normal cognitive healthy persons [2]. Magnetic resonance imaging (MRI) markers of vascular brain injury have a major clinical significance in evaluating cognition during the aging process [3]. Our previous post-mortem study shows that in elderly persons the severity of white matter changes (WMCs) is increased and also the incidence of cortical micro-bleeds (CoMBs) compared to younger ones [4]. WMCs in the temporal and occipital areas are found to be most associated with increasing age [5]. In a previous multi-center autopsy study, CoMls are identified in $10 \%$ of cognitively normal adults [6]. There is also evidence that genetic factors can be responsible for their increase $[7,8]$.

The present post-mortem study compares the incidence of cerebrovascular lesions between young-aged, middle-aged, and elderly cognitive normal persons on routine neuropathological examination and with 7.0-tesla MRI for the demonstration of the incidence and distribution of the small cerebrovascular lesions.

\section{Materials and Methods}

Forty-four patients, who had been admitted for a non-cerebral disease at the Lille University Hospital, underwent a general autopsy including the brain examination. None of them had a stroke history or known cognitive disturbances. Also none of them had carotid artery disease or atrial fibrillation. No signs of an autoimmune or inflammatory disease were observed. A previously obtained informed consent from the nearest family allowed an autopsy for diagnostic and scientific purposes. The brain tissue samples were acquired from the Lille Neuro-Bank of the Lille University, federated to the "Centre des Resources Biologiques" that acted as an institutional review board. The patients consisted of 10 young adults ( $27 \pm 3$ years), 20 middle-aged adults (52 \pm 5 years), and 14 elderly ones ( $75 \pm 7$ years).

The standard diagnostic procedure consisted of examining samples of different brain regions in order to exclude an underlying neurodegenerative disease. Only one middle-aged person 
displayed a few neurofibrillary tangles. Also the incidence of the different macroscopic and microscopic visible cerebrovascular lesions in all brain sections was evaluated. In addition, a whole coronal section of a cerebral hemisphere, at the level of the mamillary body, was taken for the semi-quantitative evaluation of WMCs, CoMBs, and CoMls. The mean values for WMCs were the average of the ranking scores: no change, a few isolated small hypo-density regions, frequent scattered ones in the corona radiata, and forming confluent lesions of myelin and axonal loss. For the other cerebrovascular lesions the mean values corresponded to their percentage number [9].

A 7.0-Tesla MRI (Bruker BioSpin SA) was used with an issuer-receiver cylinder coil of $72 \mathrm{~mm}$ inner diameter (Ettlingen, Germany), according to a previously described method. Three coronal sections of a cerebral hemisphere were submitted to T2 and T2* MRI sequences: a frontal one, a central one and one at the level of the parietal lobe. The brain sections, previously cleaned from formalin, were placed in a plastic box filled with salt-free water, of which the size did not allow significant tissue movements[10]. Semi-quantitative evaluation of incidence and severity of the small cerebrovascular lesions was evaluated in the same way as for the neuropathological examination. The ranking scores of the severity of the WMCs and of the incidence of the CoMBs and CoMls were evaluated separately in the different sections [11].

Statistical analyses were performed comparing the young -adult group to the middle-aged and the elderly groups. Unvaried comparisons of unpaired groups were performed with the Fisher's exact test for categorical data. The non-parametric Mann-Whitney $U$-test was used to compare continuous variables. The significance level, two-tailed, was set at $\leq 0.01$ for highly significant and $\leq 0.05$ for marginally significant.

\section{Results}

The vascular risk factors were different between the different age groups: arterial hypertension, hypercholesterolemia and the use of anti-thrombotic agents were found to be significantly more frequent in the elderly group and to a lesser degree in the middle-aged group compared to the young-aged group. No gender differences were observed between the different age groups: male gender percentage of $60 \%$ in the young-aged, $57 \%$ in the middle-aged, and $62 \%$ in the elderly persons (Table 1).

Table 1 Comparison of the incidence of vascular risk factors between young-aged, middle-aged and elderly persons.

\begin{tabular}{llll}
\hline Items & Young & Adult & Elderly \\
& $(n=10)$ & $(n=20)$ & $(n=14)$ \\
Arterial hypertension & $0 \%$ & $10 \%^{*}$ & $18 \% * *$ \\
Diabetes & $0 \%$ & $0 \%$ & $0 \%$ \\
Hypercholesterolemia & $0 \%$ & $15 \%^{*}$ & $28 \% * *$ \\
Smoking & $17 \%$ & $15 \%$ & $18 \%$ \\
Antithrombotic use & $0 \%$ & $15 \% *$ & $25 \% * *$ \\
\hline
\end{tabular}

$\mathrm{P}$ value $\leq 0.01^{* *} ; \mathrm{P}$ value $\leq 0.05^{*}$ on comparison with the young-aged group. 
The neuropathological examination only showed more severe WMCs and an increased number of CoMBs in the elderly group compared to the young- and middle-aged groups. No differences could be observed concerning the other cerebrovascular lesions, including the CoMIs (Table 2).

Table 2 Neuropathological comparison of the incidence of the cerebrovascular lesions between young-aged, middle-aged, and elderly persons.

\begin{tabular}{llll}
\hline Items & $\begin{array}{l}\text { Young } \\
(\mathrm{n}=10)\end{array}$ & $\begin{array}{l}\text { Adult } \\
(\mathrm{n}=20)\end{array}$ & $\begin{array}{l}\text { Elderly } \\
(\mathrm{n}=14)\end{array}$ \\
White matter changes & $0.0(0.0)$ & $0.0(0.0)$ & $1.0(0.9)^{* *}$ \\
Cerebral amyloid angiopathy & $0.0(0.0)$ & $0.0(0.0)$ & $0.0(0.0)$ \\
Lacunar infarcts & $0.0(0.0)$ & $0.0(0.0)$ & $0.0(0.0)$ \\
Territorial infarcts & $0.0(0.0)$ & $0.1(0.3)$ & $0.0(0.0)$ \\
Lobar hematomas & $0.0(0.0)$ & $0.0(0.0)$ & $0.0(0.0)$ \\
Cortical micro-infarcts & $0.0(0.0)$ & $0.0(0.0)$ & $0.0(0.0)$ \\
Cortical micro-bleeds & $0.0(0.0)$ & $0.0(0.0)$ & $0.8(0.7)^{* *}$ \\
\hline
\end{tabular}

$\mathrm{P}$ value $\leq 0.01^{* *}$ on comparison with the young-aged group

The NMR examination showed only increased severity of WMCs in the frontal and parietal sections in the elderly group. In contrast to what was observed on neuropathological examination, CoMls were increased in the central and parietal sections of the middle-aged and the elderly persons. CoMBs were increased the all three separate coronal sections of elderly as well as of middle-aged groups (Table 3). The absence of small cerebrovascular lesions on MRI is shown in a brain section of a young-aged person (Figure 1). Their presence is demonstrated in the brain sections of a middle-aged (Figure 2) and an elderly individual (Figure 3).

Table 3 Comparison of frequency and distribution of the small cerebrovascular lesions between young-aged group, and the middle-aged, and elderly groups with magnetic resonance imaging.

\begin{tabular}{llll}
\hline Items & $\begin{array}{l}\text { Young } \\
(\mathrm{n}=10)\end{array}$ & $\begin{array}{l}\text { Adult } \\
(\mathrm{n}=20)\end{array}$ & $\begin{array}{l}\text { Elderly } \\
(\mathrm{n}=14)\end{array}$ \\
$\begin{array}{l}\text { White matter changes } \\
\text { Frontal section }\end{array}$ & $0.0(0.0)$ & $0.1(0.3)$ & $0.6(0.5)^{*}$ \\
$\quad$ Central section & $0.1(0.4)$ & $0.1(0.3)$ & $0.6(0.5)$ \\
$\quad$ Parietal section & $0.3(0.5)$ & $0.0(0.0)$ & $1.0(0.7)^{*}$ \\
Cortical micro-infarcts & & & \\
$\quad$ Frontal section & $0.3(0.5)$ & $0.7(0.8)$ & $0.4(0.7)$ \\
$\quad$ Central section & $0.3(0.5)$ & $1.0(0.4)^{*}$ & $1.3(0.5)^{*}$ \\
$\quad$ Parietal section & $0.3(0.5)$ & $1.3(0.5)^{*}$ & $1.3(0.5)^{*}$ \\
Cortical micro-bleeds & & & \\
$\quad$ Frontal section & $0.3(0.5)$ & $1.3(0.6)^{*}$ & $1.1(0.3)^{*}$ \\
$\quad$ Central section & $0.9(0.6)$ & $2.1(0.5)^{* *}$ & $1.8(0.4)^{* *}$ \\
$\quad$ Parietal section & $0.8(0.7)$ & $2.3(0.5)^{* *}$ & $1.8(0.3)^{* *}$ \\
\hline
\end{tabular}

$P$ value $\leq 0.01^{* *} ; \mathrm{P}$ value $\leq 0.05^{*}$ on comparison with the young-aged group. 


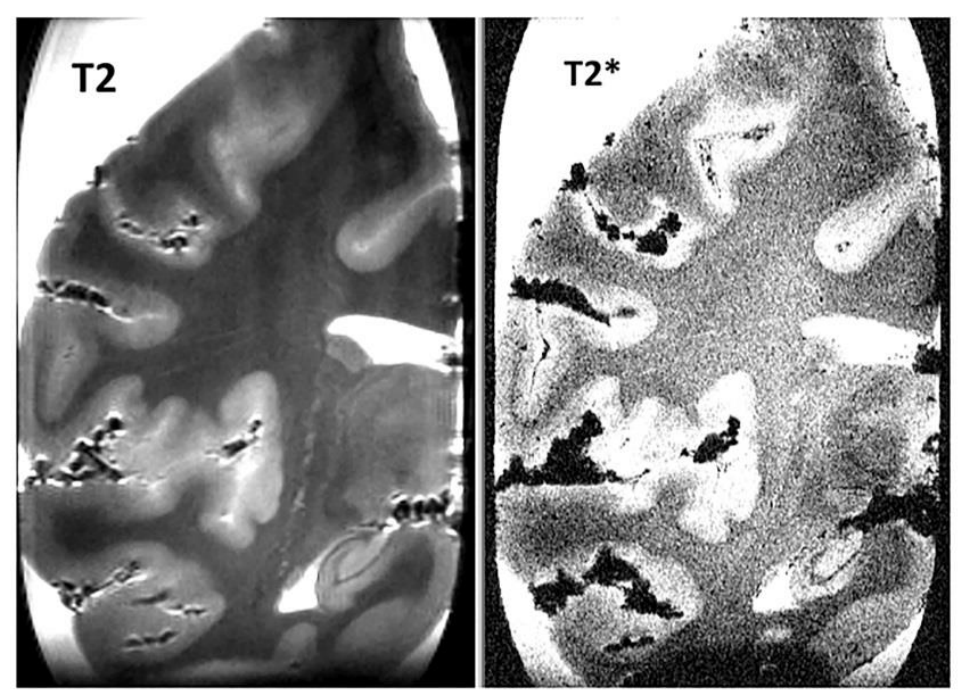

Figure $1 \mathrm{~T} 2$ and T2* sequences of a parietal cerebral coronal section in a young adult. No cortical micro-infarcts nor cortical micro-bleeds are observed. The white matter has a normal appearance on the $\mathrm{T} 2$ sequence.

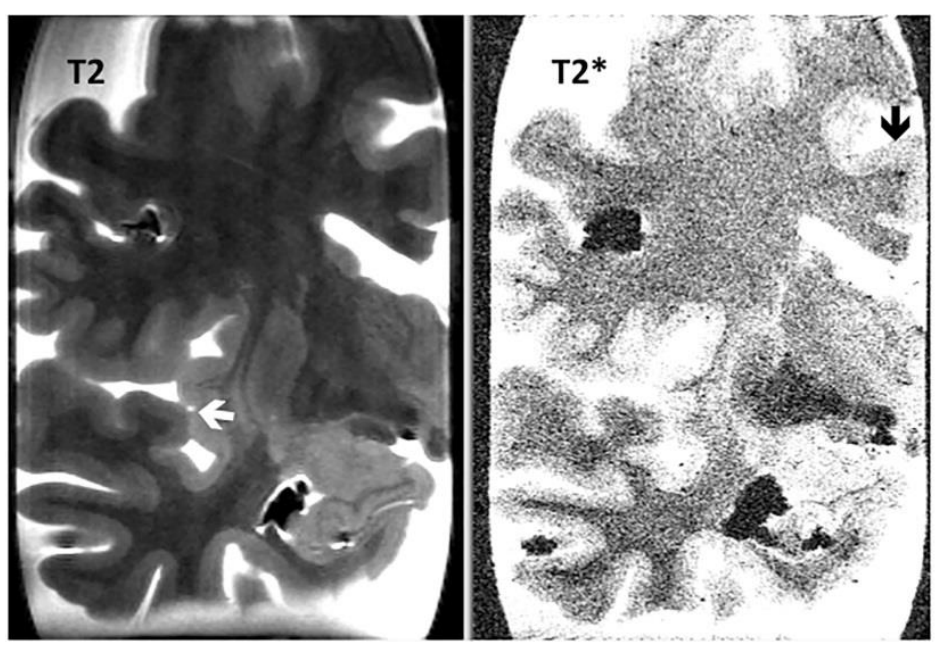

Figure $2 \mathrm{~T} 2$ and $\mathrm{T} 2 *$ sequences of a parietal cerebral coronal section in a middle-aged adult. A cortical micro-infarct is observed on the T2 sequence (white arrow). On the T2* sequence, a cortical micro-bleed (black arrow) is present. The white matter has a normal appearance on the $\mathrm{T} 2$ sequence. 


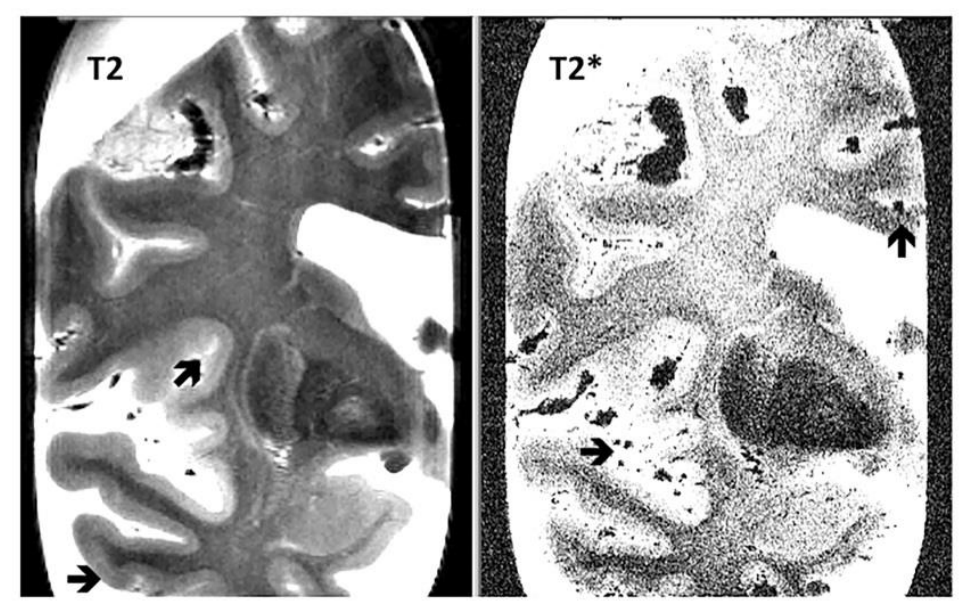

Figure $3 \mathrm{~T} 2$ and $\mathrm{T} 2 *$ sequences of a parietal cerebral coronal section in an elderly person. The T2 sequence shows two micro-infarcts (black arrows) and mild diffuse hypo-density of the white matter. The $\mathrm{T} 2 *$ sequence shows several cortical microbleeds (black arrows).

\section{Discussion}

The main MRI findings in this study show an increased severity of WMCs in the frontal and parietal sections only in the elderly population and not in the middle-aged persons when compared to the young ones. CoMls are more severe in the central and parietal sections of as well the middle-aged and elderly groups. CoMBs are augmented in all the sections of as well the middle-aged as the elderly groups.

In one study, no clear topographic areas of predilection of increase of WMCs are observed [12]. Other studies, on the other hand found a predilection of WMCs in the temporal-occipital regions with older age, arterial hypertension, and poor global cognitive function [5, 13]. Our study is in concordance with the latter one. Blood pressure has an influence on the myelin structure [14]. The magnitude of the WMCs differs according the treatment status and level of control of the arterial hypertension [15]. Midlife cardiovascular risk factors, mainly the impact of HDL cholesterol, leads to increased WMCs in later life [16]. Diabetes is also found to be associated to the presence of cerebral vascular lesions and neurodegenerative changes, leading to impaired cognitive functions such as a reduction of information-processing speed and of executive function [17]. In healthy middle-aged persons with coronary artery risk mild WMCs are observed on MRI [18].

Also in elderly persons without major risk factors for cerebrovascular diseases are the severity of WMCs and the incidence of CoMBs increased [19].

CoMls are mainly found in neurodegenerative diseases associated to cerebral amyloid angiopathy (CAA) [20]. In our study the neuropathological examination revealed no cases of CAA in the three age groups. So the CoMls must be related to the vascular risk factors and the main hallmark of a cerebrovascular influence.

The fact that the increase of CoMls is not detected on the neuropathological examination is due higher sensitivity of MRI [21].

CoMBs and WMCs are not always due to cerebrovascular disease but can also occur in Neurodegenerative diseases with a low vascular risk [22]. 
As the increase of WMCs appears only in the elderly group and not yet in middle-aged persons, these changes must be most probably related to the aging related neurodegenerative process. The increase of CoMBs, occurring in middle-aged and elderly persons, can probably be due to mixed cerebrovascular and neurodegenerative pathology.

\section{Author Contributions}

Jacques De Reuck has designed the study. Together with Florent Auger and Nicolas Durieux he performed the MRI examinations. Claude-Alain Maurage and Vincent Deramecourt performed the macroscopic and histological examinations of the brains. Charlotte Cordonnier, Florence Pasquier, Didier Leys and Regis Bordet were responsible for clinical evaluation during life.

\section{Funding}

No funding was received for the publication of this article.

\section{Competing Interests}

The authors have declared that no competing interests exist.

\section{References}

1. Caunca MR, De Leon-Benedetti A, Latour L, Leigh R, Wright CB. Neuroimaging of cerebral small vessel disease and age-related cognitive changes. Front Aging Neurosci. 2019; 11: 145.

2. Kennedy KM, Ras N. Pattern of normal age-related regional differences in white matter micro-structure is modified by vascular risk. Brain Res. 2009; 1297: 41-56.

3. Debette S, Schilling S, Duperron MG, Larsson SC, Markus HS. Clinical significance of magnetic resonance imaging markers of vascular brain injury: A systematic review and meta-analysis. JAMA Neurol. 2019; 76: 81-94.

4. De Reuck J, Auger F, Durieux N, Deramecourt V, Maurage CA, Pasquier F, et al. Cerebrovascular lesions during normal aging: A neuropathological study with 7.0-tesla magnetic resonance imaging. EC Neurol. 2018; 10: 229-235.

5. Artero S, Tiemeier H, Prins ND, Sabatier R, Breteler MM, Ritchie K. Neuroanatomical location and clinical correlates of white matter lesions in the elderly. J Neurol Neurosurg Psychiatry. 2004; 75: 1304-1308.

6. Sonnen JA, Santa Cruz K, Hemmy LS, Woltjer R, Leverenz JB, Montini KS, et al. Ecology of the aging human brain. Arch Neurol. 2011; 68: 1049-1056.

7. Carmelli D, DeCarli C, Swan GE, Jack LM, Reed T, Wolf PA, et al. Evidence for genetic variance in white matter hyperintensity volume in normal elderly male twins. Stroke.1998; 29: 11771181.

8. Rojas S, Brugulat-Serrat A, Bargallo N, Minguillon C, Tucholka A, Falcon C, et al. Higher prevalence of cerebral white matter hyperintensity in homozygous APOE-3 allele carriers aged 45-75: Results from the ALFA study. J Cerrb Blood Flow Metab. 2017; 28: 250-261.

9. De Reuck J, Deramecourt V, Cordonnier C, Leys D, Pasquier F, Maurage CA. Prevalence of small cerebral bleeds in patients with a neurodegenerative dementia: A neuropathological study. J Neurol Sci. 2011; 300: 63-66. 
10. De Reuck J, Auger F, Cordonnier C, Deramecourt V, Durieux N, Pasquier F, et al. Comparison of 7.0-TE magnetic resonance imaging of cerebral bleeds in post-mortem brain sections of Alzheimer patients with their neuropathological correlates. Cerebrovasc Dis. 2011; 31: 511517.

11. De Reuck J, Maurage CA, Deramecourt V, Pasquier F, Cordonnier C, Leys D, et al. Aging and cerebrovascular lesions in pure and in mixed neurodegenerative and vascular dementia brains: A neuropathological study. Folia Neuropathol. 2018; 56: 81-87.

12. Lindemer ER, Greve DN, Fischl BR, Augustinack JC, Salat DH. Regional staging of white matte signal abnormalities in aging and Alzheimer's disease. Neuroimage Clin. 2017; 14: 156-165.

13. Kern KC, Wright CB, Bergfield KL, Fitzhugh MC, Chen K, Moeller JR, et al. Bloodpressure control in aging predicts cerebral atrophy related to small-vessel white matter lesions. Front Aging Neurosci. 2017; 9: 132.

14. Salat DH, Williams VJ, Leritz EC, Schnyer DM, Rudolph JL, Lipsitz LA, et al. Inter-individual variation in blood pressure is associated with regional white matter integrity in generally healthy older adults. Neuroimage. 2012; 59: 181-192.

15. Haight T, Nick Bryan R, Erus G, Hsieh MK, Davatzikos C, Nasrallah I, et al. White matter microstructure, white matter lesions, and hypertension: An examination of early surrogate markers of vascular-related brain change in midlife. Neuroimage Clin. 2018; 18: 753-761.

16. Aljondi R, Szoeke C, Stewart C, Gorelik A, Desmond P. The effect of midlife cardiovascular risk factors on white matter hyperintensity volume and cognition two decades later in normal ageing women. Brain Imaging Behav. 2020; 14: 51-61.

17. Qiu C, Sigurdsson S, Zhang Q, Jonsdottir MK, Kjartansson O, Eiriksdottir G, et al. Diabetes, markers of brain pathology and cognitive function: The age, gene/environment susceptibilityReykjavik study. Ann Neurol. 2014; 55: 138-146.

18. Narallah IM, Hsieh MK, Erus G, Battapady H, Dolui S, Detre JA, et al. White matter lesion penumbra shows abnormalities on structural and physiologic MRIs in the coronary artery risk development in young adult cohort. Am J Neuroradiol. 2019; 40: 1291-1298.

19. Chowdhury MH, Nagai A, Bokura H, Nakamura E, Kobayashi S, Yamaguchi S. Age-related changes in white matter lesions, hippocampal atrophy, and cerebral microbleeds in health subjects without major cerebrovascular risk factors. J Stroke Cerebrovasc Dis. 2011; 20: 302309.

20. De Reuck J. The impact of cerebral amyloid angiopathy in neurodegenerative and cerebrovasular diseases. EC Neurol. 2019. 11: 01-02 (2019).

21. De Reuck J, Deramecourt V, Auger F, Durieux N, Cordonnier C, Devos D, et al. Post-mortem 7.0-tesla magnetic resonance study of cortical microinfarcts in neurodegenerative diseases and vascular dementia with neuropathological correlates. J Neurol Sci. 2014; 346: 85-89.

22. De Reuck J, Deramecourt V, Cordonnier C, Auger F, Durieux N, Bordet R, et al. Detection of microbleeds in post-mortem brains of patients with frontotemporal lobar degeneration: $A$ 7.0-Tesla magnetic resonance imaging study with neuropathological correlates. Eur J Neurol. 2012; 19: 1355-1360. 


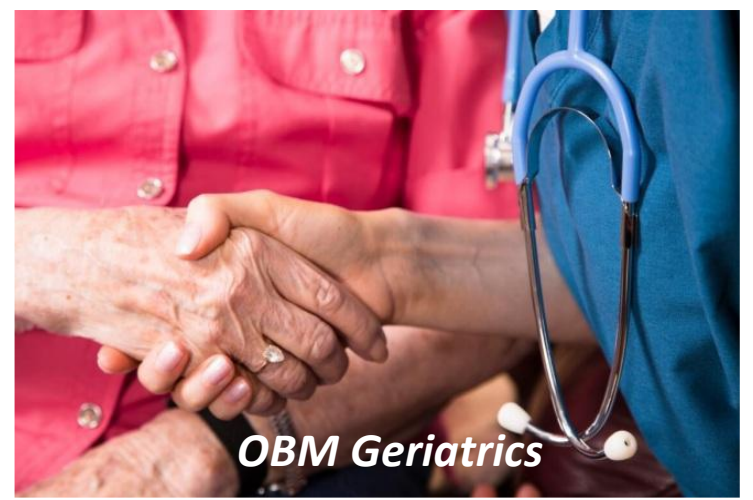

Enjoy OBM Geriatrics by:

1. Submitting a manuscript

2. Joining in volunteer reviewer bank

3. Joining Editorial Board

4. Guest editing a special issue

For more details, please visit:

http://www.lidsen.com/journals/geriatrics 